\title{
Evaluation of an indigenous fishing calendar using recreational catch rates of snapper Pagrus auratus in the North Island of New Zealand
}

\author{
R. B. Millar ${ }^{1, *}$, J. E. McKenzie ${ }^{2}$, J. D. Bell ${ }^{3}$, L. D. Tierney ${ }^{4}$ \\ ${ }^{1}$ Department of Statistics, University of Auckland, Private Bag 92019, Auckland, New Zealand \\ ${ }^{2}$ Department of Mathematics and Statistics, University of Otago, PO Box 56, Dunedin, New Zealand \\ ${ }^{3}$ Department of Marketing, University of Otago, PO Box 56, Dunedin, New Zealand \\ ${ }^{4}$ Ministry of Fisheries, Private Bag 1926, Dunedin, New Zealand
}

\begin{abstract}
Recreational fishers participating in a 12 mo diary survey provided per-trip data on number of snapper Pagrus auratus caught per unit effort (CPUE) in upper North Island, New Zealand. These data were analyzed for seasonal trends, differences between lunar quarters, and for an ordinal relatıonship with the daily ranking (on a scale of 1 to 5) of the duration of active feeding as predicted by a Maori fishung calendar A strong seasonal trend explained $30 \%$ of the variation in CPUE, with CPUE peaking in early April and subsequently declining until late August. There was modest evidence of both a difference in CPUE between lunar quarters, and a relationship with the rankings of feeding duration given by the fishing calendar $(\mathrm{p}$-values $\approx 0.1)$, but neither explained more than $2 \%$ of the variation in seasonally detrended CPUE. Days having the highest ranking of feeding duration sometimes had below average CPUE, but were never among the extremely low CPUE days. Conversely, days having the lowest ranking of feeding duratıon sometimes had above average CPUE, but never had extremely high CPUE.
\end{abstract}

KEY WORDS: Fishing calendar CPUE - Snapper Lunar effects - Seasonal effects New Zealand Recreational fishing

\section{INTRODUCTION}

Many documented accounts of lunar (29.5 d) rhythms in marine species concern migratory or spawning behaviour which is prompted by the height of the tide. For example, Californian grunion Leuresthes tenuis and capelin Mallotus villosus come ashore on beaches to spawn and generally do so on the spring high tides within the lunar cycle (Gibson 1978. Scott \& Scott 1988). Spring low tides cause the prawn Penaeus merguiensis to move from mud-bank to deeper channels (Vance \& Staples 1992).

Catch rates of some commercial fishing gears increase during certain moon phases and the reason is not always clear. Trawl catches of clupeids (e.g. her-

\footnotetext{
•E-maıl: greebie@scitec.auckland.ac.nz
}

ring and sardine) are higher around the full moon with possible causes including intensity of light, effect of currents, and behaviour of fishermen (Blaxter \& Holliday 1963, Gibson 1978). Collins (1979) showed that gillnet catch rates of lake whitefish Coregonus clupeaformis declined during the full moon phase, possibly due to increased nighttime visibility of the gillnet filament. Evidence of higher trawl catch rates of butterfish Peprilus burti during the first quarter phase has been given by Render \& Allen (1987), and Courtney et al. (1996) found that catches of eastern king prawn Penaeus plebejus peaked around the full moon.

Our literature review did not reveal any studies of lunar cycles within marine recreational fisheries or of lunar induced behaviour that could give rise to a change in quality of such fishing. Nonetheless, many marine anglers are keen believers in the role of lunar cycles in fish catchability and use fishing calendars to 
predict the quality of fishing on a given day. In New Zealand, the fishing calendar predominantly used is based on Maori lore specifying the optimal lunar phases for food production activities, including agricultural, fluvial and marine (Best 1929).

A 12 mo diary survey of recreational marine fishing in upper North Island, New Zealand, provided an opportunity to investigate for lunar cycles and for the predictive capability of the Marri fishing calendar on the recreational catch rates of snapper Pagrus auratus, the most popular recreational species in New Zealand.

\section{DATA}

As part of its national research initiative the recreational fisheries working group of the New Zealand Ministry of Agriculture and Fisheries conducted a year-long diary survey of a sample of recreational fishers in upper North Island, New Zealand (MAF Fisheries 1995), from Tirua Point to Cape Runaway (Fig. 1). Participating fishers were chosen using a random phone survey of all households with listed phone numbers in the region. Of the 15015 households phoned, 3363 contained eligible fishers (15 yr or older and not a commercial fisher), of which 2728 agreed to participate in the survey by keeping a fishing diary of each trip

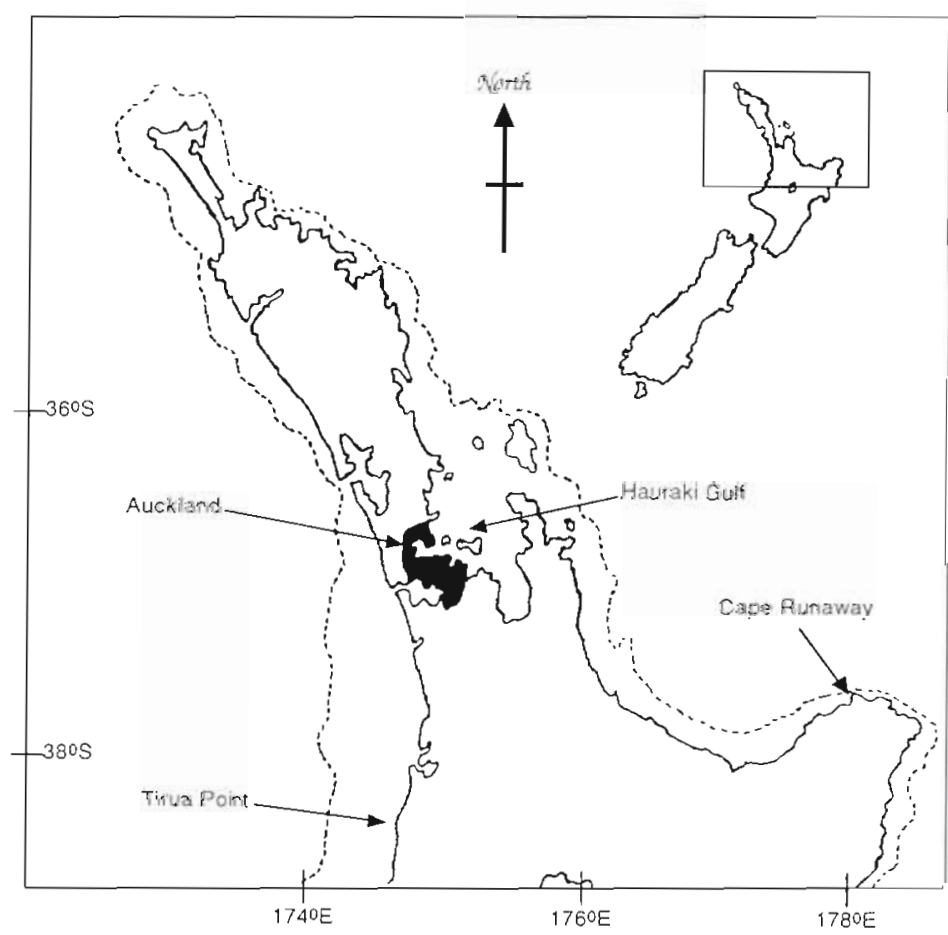

Fig. 1 Upper North Island of New Zealand and the $100 \mathrm{~m}$ depth contour (dashed line). The recreational marine fishing diary survey covered the area north of Tirua Point and west of Cape Runaway undertaken in the 12 mo period from 1 December 1993 to 30 November 1994.

The diary information included date of trip, hours spent fishing, type of fishing done (e.g. rod, net, diving, from boat/shore), species targeted, and the number of each species caught. Fishers were requested to provide catch weight of each species where possible. Information was not recorded on fishing location, weather and sea state, time of day, bait used, etc, or on the activities and catches of fishing companions.

Snapper Pagrus auratus is by far the most important recreational marine species in New Zealand. Pagrus auratus is also present off Japan, Taiwan, China, Philippines, Indonesia, southern Australia, and Lord Howe and Norfolk Islands (Paul 1992). In New Zealand snapper range down to the northern end of South Island, but the vast majority ( $>95 \%$ ) of the recreational catch of snapper is taken in the region covered by the present survey. Snapper are bottom feeders and prefer depths up to $100 \mathrm{~m}$ (Armitage et al. 1981, Paul 1992). At the time of the survey the minimum legal size was $25 \mathrm{~cm}$ (about $0.4 \mathrm{~kg}$ ), but has since been increased to $27 \mathrm{~cm}$. Snapper mature at 25 to $30 \mathrm{~cm}$ in length and occasionally grow to over $80 \mathrm{~cm}$ and more than $10 \mathrm{~kg}$.

The diary information gave the total time spent fishing but not the time spent fishing for each species targeted during the trip. Hence, only those trips in which snapper was the sole species targeted $(72 \%$ of all trips in which snapper were targeted) were used. The majority $(78 \%)$ of these trips deployed rods or handlines from boats, and to avoid comparison between different modes of fishing the analysis was confined to this mode of fishing alone. This left a total of 5032 fishing trips by 923 fishers.

Previous analyses of lunar effects in commercial fisheries have assigned each day to a lunar quarter (e.g. Collins 1979, Render \& Allen 1987, Vance \& Staples 1992). This was done here by assigning each day to the lunar quarter corresponding to the lunar phase (new moon, first quarter, full moon, and last quarter) closest to noon of that day, as determined from the British Astronomical Association handbooks for 1993 and 1994.

There are some minor variations on the Maori fishing calendar. We unanimously agreed upon one published version (Hohepa 1993, 1994) as being by far the most widely accepted in New Zealand. This calendar is retailed throughout New Zealand and timely portions of it also appear in a number of maga zines and newspapers. It is written primarily for recreational snapper fishing, specifying a time at which snapper will begin to feed and 


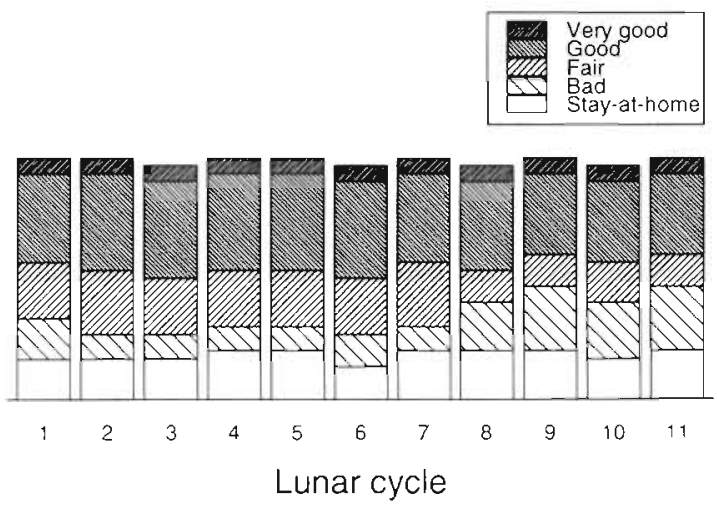

Fig. 2. Barplot showing the relative frequency of the 5 fishing calendar rankings within the 11 complete lunar cycles in the diary survey period 1 December 1993 to 30 November 1994

assigning each day a ranking from 1 to 5 (stay-at-home, bad, fair, good, and very good, respectively) according to the length of time for which they will be feeding. The fishing calendar is largely based on the lunar cycle with very good feeding periods predicted for $2 \mathrm{~d}$ after the last quarter followed by up to $10 \mathrm{~d}$ of good feeding. There is a non-lunar component also. For example, during the 12 mo study period the number of days in a lunar cycle with a calender ranking of bad varied from 3 to 8 (Fig, 2).

\section{ANALYSIS}

Catch per unit effort (CPUE) for each trip was calculated as the number of snapper caught divided by the number of hours spent fishing. This measure of CPUE was chosen in preference to catch weight per hour because the catch weight was provided in only $58 \%$ of the successful fishing trips. Moreover, comparison with a smaller scale boatramp survey showed that catch weights recorded in the diary survey tended to be overestimated.

The CPUE data are very non-normal (Fig. 3) and nearly $28 \%$ of the trips were unsuccessful (CPUE $=0$ ) The maximum CPUE was 14.7 from a trip of $1.5 \mathrm{~h}$ duration in which 22 snapper were caught

In addition to seasonal, lunar and fishing calendar effects, a comprehensive statistical model of the CPUE data would also include day effects and fisher effects. Seasons, lunar phases and fishing calendar rankings are all predetermined and correspond to fixed effects, whereas the vagaries of weather and abiotic factors cause the day effect to be random. The fishers, being randomly chosen, also correspond to random effects. Procedures do not exist for fitting (possibly nonlinear) mixed effects models to data that are so grossly nonnormal (Fig 3) and hence more appropriate nonparametric methods were employed.

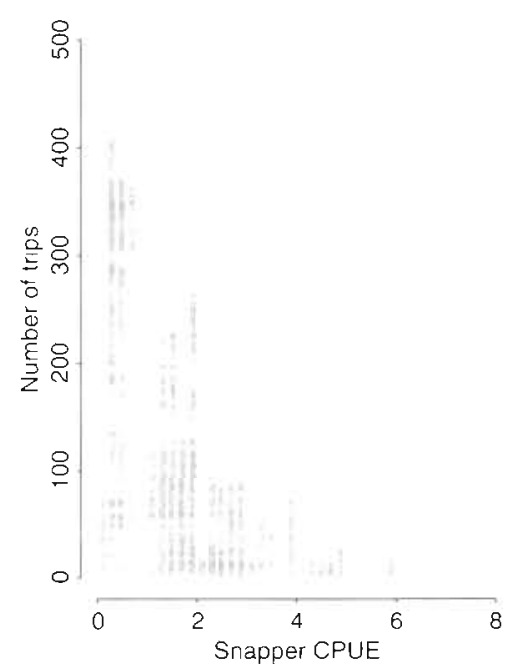

Fig. 3. Histogram of non-zero catch per unit effort (CPUE) data. There were also 1384 unsuccessful trips (CPUE $=0)$ and another 19 trips with CPUEs between 8.1 and 14.7

Two nonparametric analyses were performed. The first used daily CPUEs, calculated by averaging over all individual trips (weighted by trip duration) undertaken on that day. Note that these daily CPUEs include between-fisher variability because it will be a different set of fishers active each day. The second nonparametric analysis was aimed at eliminating the betweenfisher variability by ranking CPUEs within each individual fisher prior to analysis.

Analysis 1, using daily CPUEs. Nonparametric analyses were performed on the daily CPUEs, calculated as the total daily catch divided by the total hours fished for the day. Total hours fished each day averaged 50.4 over the $12 \mathrm{mo}$ period and varied from a high of $356(28 \mathrm{Dec})$ to a low of zero on 16 days in the June to October period when no eligible snapper trips were undertaken by survey participants. Over the 349 days fished the 5 fishing calendar rankings (stay-at-home, bad, fair, good, very good) had frequencies of 63,59 . 72,131 and 24 , respectively,

A strong seasonal effect is evident (Fig. 4), with daily CPUE peaking in early April and subsequently declining until late August. A seasonal trend was fitted using a quadratic weighted local least squares regression, implemented using Splus function loess (Chambers \& Hastie 1992) with daily CPUE weighted by hours fished. (Approximate $F$-tests indicated a span of $2 / 3$ to be most appropriate for the loess fit.)

The residuals from the loess fit exhibited an increase in variability with increasing fitted CPUE. The daily CPUE is count data averaged over fishing time, and the natural variance stabilizing transformation is square-root (Agresti 1990). Hence, the loess fit was repeated, this time fitting to the square-root of daily 

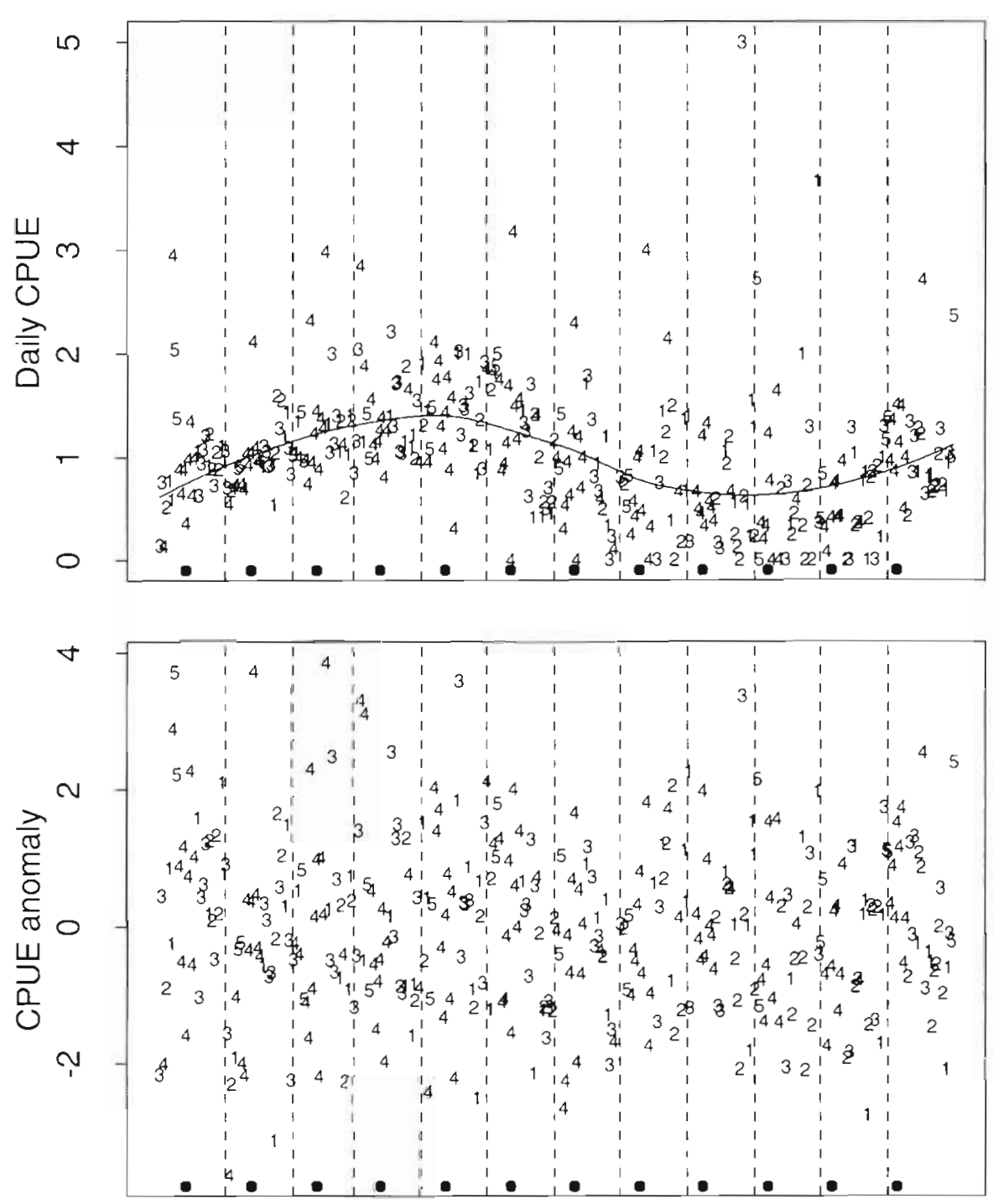

Dec Jan Feb Mar Apr May June Jul Aug Sep Oct Nov

Month
Fig. 4. Daily CPUEs showing a strong seasonal trend (upper plot). The plotting symbol is the fishing calendar ranking (1: stayat-home, 2: bad, 3: fair, 4: good, 5: very good). The solid dots ( indicate the days of the new moon. The CPUE anomalies (lower plot) were obtaned as the weighted residuals from a local least squares fit to the squareroot of the dally CPUE data
CPUE. The (weighted) residuals from this fit give the CPUE anomalies to be investigated for a relationship with the fishing calendar and lunar phase (Fig 4).

A Kruskal-Wallis test was used to test for a relationship between Iunar quarter and CPUE anomaly. This test looks for any difference in fishing quality between the 4 quarters.

The fishing calendar contains a seasonal component (Fig. 2) and so it was tested for a relationship with both the daily CPUEs and CPUE anomalies (Fig 4). A nonparametric Jonckheere-Terpstra 1-way test for ordered alternatives (Lehmann 1975, Pirie 1983) was used because it is more powerful than the Kruskal-Wallis in applications where the direction of the possible effect is known. The null hypothesis of no difference can be written as $H_{0}: F_{1}=F_{2}=F_{3}=F_{4}=F$, where $F_{i}$ is the distribution function for CPUE (or CPUE anomaly) on a day with predicted feeding duration ranking of $i, i=1$ (stay-at-home), 2 (bad), 3 (fair), 4 (good), or 5 (very good). The Jonckheere-Terpstra test uses the alternative hypothesis $H_{1} . F_{1} \geq F_{2} \geq F_{3} \geq F_{4} \geq F_{5}$ (with at least 1 strict inequality). Here, the notation $F_{i} \geq F_{1+1}$ is used to denote $F_{i}(x) \geq F_{1+1}(x)$ for all $x \geq 0$. That is,

$\operatorname{Prob}_{1}(\mathrm{CPUE} \leq x) \geq \operatorname{Prob}_{l+1}(\mathrm{CPUE} \leq x)$ for all $x \geq 0$

where Prob, and Prob ${ }_{1+1}$ denote probabilities for calendar rankings $i$ and $i+1$, respectively. Eq. (1) states that under the alternative hypothesis $H_{1}$ the probability of the CPUE being below an amount $x$ will be higher (or equal) on a day with lower fishing calendar ranking 
Analysis 2, using within-fisher normalized daily CPUEs. The use of daily CPUEs and CPUE anomalies in the above analysis ignores the random effect of between-fisher variability. In addition to differing levels of fishing skill, between-fisher variability also includes differences in fishing spot, baits and other habits, and one would expect a more powerful test to be provided by comparing CPUEs within fishers. If fisher $j$ completed $n_{j}$ trips, then the within-fisher normalized CPUEs were computed as (David 1981)

$$
z_{i j}=\Phi^{-1}\left(\frac{R_{i j}-\frac{3}{8}}{n,+\frac{1}{4}}\right), \quad i=1, \ldots, n_{i}
$$

where $R_{1 /}$ is the rank of the ith trip performed by fisher $j$ and $\Phi$ is the standard normal cumulative distribution.

The previous analysis was repeated with the individual trip CPUE data replaced by the $z_{i j}$ values from Eq. (2). It was not necessary to square-root the daily average of the $z_{i j}$ values (prior to the loess fit) because the $Z_{i j}$ 's values have standardized variance.

\section{RESULTS AND DISCUSSION}

The seasonal trend fitted by local least squares explained $30 \%$ of the variability in daily CPUEs (Fig. 4). This trend is well known in snapper and is due to their winter movement to the relatively warmer water that is found at greater depths of fshore. In spring (November to December) the adults begin to congregate at intermediate depths for spawning and by summer and through to early autumn they are feeding closer inshore (Paul 1992) and more available to recreational fishers. Some larger snapper do not follow this annual movement because they are better able to withstand the colder winter temperature inshore. Hence, the reduced CPUE (number of snapper caught per hour fished) over winter does not immediately imply a reduction in catch weight per hour fished.

There is a limited amount of evidence suggesting a relationship between CPUE and both the fishing calendar and lunar quarters, but it is not significant at the $5 \%$ level (Table 1 ) and neither relationship explains more than $2 \%$ of the variation in daily CPUE or CPUE anomaly (over both analyses 1 and 2). When averaged over the lunar cycle (Fig. 5), the CPUE anomalies (from analysis 1) and fishing calendar predictions show the same general decline about $4 \mathrm{~d}$ into the lunar cycle and an increase around the 18th day. (The average fishing calendar predictions were calculated using the ordinal values $1-5$ and hence are very heuristic.)

It is interesting to take a closer look at the CPUE anomalies (Fig 4) from analysis 1. The top $14 \mathrm{CPUE}$ anomalies are all from days ranked fair, good, or very good by the fishing calendar, including 2 predicted
Table 1 Significance levels of the nonparametric hypothesis tests from the 2 analyses. The Jonckheere-Terpstra (JT) tests for the ordered alternative hypothesis that CPUE increases in the order of the predicted feeding durations: stay-at-home, bad, fair, good, and very good. The Kruskal-Wallis (KW) tests for any difference in CPUE between the 4 lunar quarters

\begin{tabular}{|ccc|}
\hline & Analysis 1 & Analysis 2 \\
\hline $\begin{array}{l}\text { Fishing calendar: } \\
\text { Daily CPUE, JT }\end{array}$ & 0.12 & 0.06 \\
$\begin{array}{l}\text { CPUE anomaly, JT } \\
\text { Lunar quarter: } \\
\text { CPUE anomaly, KW }\end{array}$ & 0.09 & 0.12 \\
& 0.12 & 0.07 \\
\hline
\end{tabular}

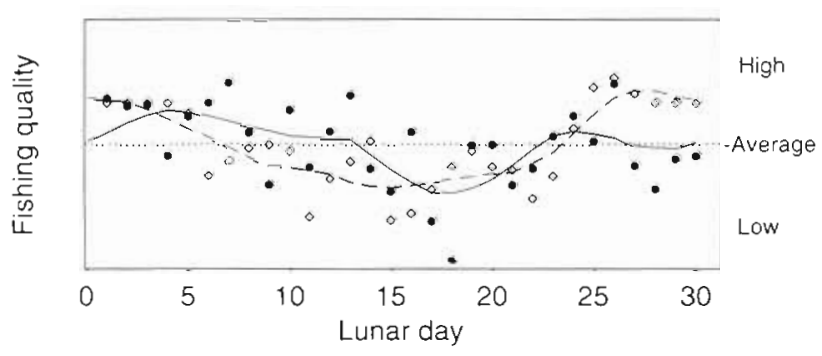

Fig. 5. CPUE anomalies ( $\bullet$ from analysis 1 and fishing calendar ranking $(\diamond)$, averaged over the lunar cycle (new moon = Day 1). Local least squares fits are overlaid

rankings of very good. These 3 rankings constitute 227 of the 349 days fished and the p-value (under $H_{0}$ : no relationship with calendar) for the observation that they have the top 14 CPUE anomalies is $0.0021=(227 / 349 \times$ $226 / 348 \times \ldots \times 214 / 336$ ). Of the days with lowest CPUE anomalies, many rankings of fair and good are present ( 9 of the lowest 14), but none of very good. In fact the worst of the days predicted as very good was the day with the 63rd lowest CPUE anomaly. There are 24 days with very good rankings and the p-value (under $H_{0}$ ) for the observation that the worst of these days is the 63rd lowest is $0.0076=(325 / 349 \times 324 / 348 \times \ldots \times 264 / 288)$.

The above p-values can not formally be taken as significant evidence (at the $5 \%$ level) against $H_{0}$ because the tests were not specified a priori, but they do suggest that a day predicted to be stay-at-home or bad will not achieve an extremely high CPUE, and a day that is predicted as very good will not have an extremely low CPUE (Fig 6). The evidence against $H_{0}$ must be tempered by the observation that the day with lowest CPUE anomaly (2 January 1994) was predicted to have a good feeding duration. An investigation of 2 January was undertaken to look for factors that could have caused it to return the lowest CPUE if indeed the feeding prediction was correct. One possible explanation is simply that 2 January occurs during a period of very intense recreational snapper fishing and snapper con- 


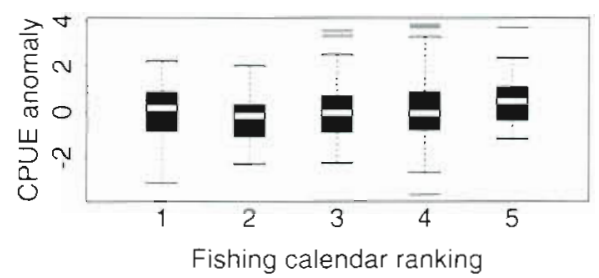

Fig. 6. Boxplots of CPUE anomalies (from analysis 1) by fıshing calendar ranking. The upper and lower sides of the box equal the upper and lower quartiles respectively, and the median is displayed within each box

centrations could have been temporarily diminished. The weather does not appear to be the reason because weather details from the New Zealand Herald newspaper showed that the weather was not atypical during the week surrounding 2 January 1994. A very interesting feature of 2 January is that it lies outside of the contiguous block of approximately $12 \mathrm{~d}$ of good and very good predictions that straddles each new moon. Most lunar cycles include just 1 day with a prediction above fair outside of this block, and 2 January 1994 was such a day. It is immediately followed by predictions of bad and stay-at-home.

A difficulty in detecting any effect of the fishing calendar using the available data is the lack of information concerning the time at which fishing took place. The fishing calendar gives predicted start times and durations of active feeding rather than a direct measure of predicted CPUE. If, for example, fishing is done only over the feeding period then CPUE will be independent of the calendar rankings. However, a one-way Jonckheere-Terpstra test of the calendar's predicted feeding duration on average daily trip duration gave no indication ( $p$-value $=0.9$ ) of an increase in trip duration with increasing duration of predicted feeding time and so it should be reasonable to assume that a ranking in length of predicted feeding period corresponds to a ranking in predicted CPUE.

A boatramp interview survey covering the inner and western Hauraki Gulf (Fig 1) was conducted between 14. February 1994 and 19 June 1994. Corroboration of diary data with the boatramp interview data has shown that successful trips tended to be dutifully recorded by the diarists, but that there was some under-reporting of unsuccessful trips. The daily proportions of under-reparted zero CPUE trips are unlikely to depend on the predicted feeding duration, and hence the implied ranking of predicted CPUEs remains intact. However, it does make detection of any effect of these rankings more difficult.

This study, and the studies of Collins (1979) and Vance \& Staples (1992), have presented analyses in which some covariance structure of individual trip (or. haul) CPUE data is acknowledged. Here, this was implicitly done by using daily average CPUEs rather that individual trip CPUEs. The latter approach ignores the possibility that replicate trips on the same day may not be independent due to a day effect. The ANOVA performed by Render \& Allen (1987) did use individual haul data and consequently the statistically significant difference that was detected between the CPUEs of the lunar quarters may be questionable.

Acknowledgements. We are grateful to Cam Gilbert (Dept of Statistics, Univ. of Otago) for production of Fig. 1, and to Bill Hohepa (Maraeti Beach, Auckland) for information on the background of the Maori fishing calendar

\section{LITERATURE CITED}

Agresti A (1990) Categorical data analysis. Wiley, New York Armitage RO, Payne DA, Lockley GJ, Currie HM, Colban RL, Lamb BG. Paul LJ (1981) Guide book to New Zealand commercial fish species. New Zealand Fishing Industry Board, Wellington

Best E (1929) Fishing methods and devices of the Mauri. Dominion Museum Bulletin No. 12, Government Printer, Wellington

Blaxter JHS, Holliday FGT (1963) The behaviour and physiology of herring and other clupeids. In: Russell FS (ed) Advances in marıne biology, Vol 1 Academic Press, London, p 262-393

Chambers JM, Hastie TJ (1992) Statistıcal models in $\mathrm{S}$ Wadsworth and Brooks/Cole, Pacific Grove, CA

Collins JJ (1979) Relative efficiency of multifilament and monofilament nylon gill net towards lake whitefish (Coregonus clupeaformis) in Lake Huron. J Fish Res Bd Can 36: $1180-1185$

Courtney AJ, Die DJ, McGilvray JG (1996) Lunar periodicity in catch rate and reproductive condition of adult eastern king prawns, Penaeus plebejus, in coastal waters of south-eastern Queensland. Australia. Mar Freshwat Res 47:67-76

David HA (1981) Order statistics, 2nd edn. Wiley, New York

Gibson RN (1978) Lunar and tidal rhythms in fish. In: Thorpe JE (ed) Rhythmic activity of fishes. Academic Press, London, p 201-213

Hohepa B (1993) The 1993-4 Maori fishing calendar. PO Box 56, Maraetai Beach, Auckland 1705

Hohepa B (1994) The 1994-5 Maori fishing calendar. PO Box 56. Maraetai Beach، Auckland 1705

Lehmann EL (1975) Nonparametrics: statistical methods based on ranks. Holden-Day, San Francisco

MAF Fisheries (1995) Determining the recreational share of New Zealand's marine harvest: it's in the bag. Seafood NZ, May '95:28-32

Paul LJ (1992) The biology of snapper. In: Mossman S (ed) Ail you want to know about snapper. NZ Fishing News, Auckland, p 3-15

Pirie W (1983) Jonckheere tests for ordered alternatives. In Kotz S, Johnson NL, Read CB (eds) Encyclopedia of statistical sciences, Vol 4. Wiley, New York, p 315-318

Render JH. Allen RL (1987) The relationship between lunar phase and Gulf butterfish, Peprilus burti, catch rate. Fish Bul] 85:817-819

Scott WB, Scott MG (1988) Atlantıc fishes of Canada. Can Bull Fish Aquat Sci. 219

Vance DJ, Staples DJ (1992) Catchability and sampling of three species of juvenile penaeid prawns in the Embley River, Gulf of Carpentaria, Australia. Mar Ecol Prog Ser 87.201-213 